\title{
Residual Stress Measurements of Alumina-Zirconia Ceramics by Time-of-Flight Neutron Diffraction
}

\author{
Kunyang Fan ${ }^{1}$, Jesus Ruiz-Hervias ${ }^{1 a^{*}}$, Jonas Gurauskis ${ }^{2}$, C. Baudin ${ }^{2}$ \\ ${ }^{1}$ Materials Science Department, Universidad Politécnica de Madrid, E.T.S.I. Caminos, Canales \\ y Puertos, Profesor Aranguren 3, E-28040 Madrid, Spain \\ ${ }^{2}$ Instituto de Cerámica y Vidrio, CSIC, Kelsen 5, E-28049 Madrid, Spain \\ ajesus.ruiz@upm.es
}

\section{Keywords: Ceramic Composites, Residual Stress, Neutron Diffraction, Tape Casting}

\begin{abstract}
Neutron strain scanning and Rietveld analysis were used to study the residual stresses in $\mathrm{Al}_{2} \mathrm{O}_{3} / \mathrm{Y}$-TZP ceramic composites fabricated by different green processing techniques (a novel tape casting and conventional slip casting) and with different zirconia content. The results show that the residual stresses in zirconia particulates are tensile and the ones in alumina matrix are compressive, with almost flat through-thickness residual stress profiles in all bulk samples. The residual stresses for both phases were mainly dependent on the zirconia content, irrespective of the measurement direction and the fabrication process.
\end{abstract}

\section{Introduction}

Alumina-zirconia ceramics have received considerable attention in both engineering and academic fields due to their improved mechanical properties when compared with pure alumina ceramics [1-4]. It has been proposed that the residual stresses due to thermal and elastic mismatches between alumina and zirconia could contribute to toughening and enhance the structural performance of these ceramic composites $[5,6]$.

Numerous works have been done on residual stresses analysis in $\mathrm{Al}_{2} \mathrm{O}_{3}-\mathrm{ZrO}_{2}$ composites [6-10] and a wide range of results were obtained depending on fabrication routes, composition design and measurement techniques. In this study $\mathrm{Al}_{2} \mathrm{O}_{3} / \mathrm{Y}$-TZP (alumina/tetragonal $\mathrm{ZrO}_{2}$ stabilized with 3 $\mathrm{mol} \% \mathrm{Y}_{2} \mathrm{O}_{3}$ ) composites were investigated. Samples were prepared by a novel tape casting route [11, 12] for stacking green ceramic tapes made from high solid content of water-based slurries at room temperature and using low pressures. The conventional slip casting [13] was taken as reference for comparison. The effect of the Y-TZP content on the $\mathrm{Al}_{2} \mathrm{O}_{3} / \mathrm{Y}-\mathrm{TZP}$ composites was also studied.

Time-of-flight (TOF) neutron diffraction and Rietveld analysis have been applied for the nondestructive determination of the residual stresses in $\mathrm{Al}_{2} \mathrm{O}_{3} / \mathrm{Y}$-TZP bulk samples. Through-thickness residual stress profiles corresponding to both phases, i.e. alumina and zirconia, were obtained, and compared to available data in the literature and to estimations by theoretical models. The effects of Y-TZP content and the new processing method on the microstructure and residual stresses of the ceramic composites were established.

\section{Experimental}

\section{Sample preparation and characterization}

Monoliths of $\mathrm{Al}_{2} \mathrm{O}_{3} / \mathrm{Y}$-TZP composites with 5 and 40 vol. \% of Y-TZP were obtained using highpurity $\alpha-\mathrm{Al}_{2} \mathrm{O}_{3}$ and polycrystalline tetragonal zirconia stabilized with 3 mol. $\% \mathrm{Y}_{2} \mathrm{O}_{3}$, named as $\mathrm{Y}$ TZP, as the starting powders. Two kinds of green processing methods were used for each composition: the novel tape casting and conventional slip casting. The studied specimens were named as A-5YTZP(slip), A-5YTZP(tape), A-40YTZP(slip) and A-40YTZP(tape), in order to 
describe compositions and fabrication techniques. Subsequent sintering was carried out at a maximum temperature of $1500^{\circ} \mathrm{C}$, with a dwell time of $2 \mathrm{~h}$ (heating and cooling rates of $5^{\circ} \mathrm{C} / \mathrm{min}$ ).

High-density (relative density $>98.5 \%$ ) sintered samples were obtained for each studied $\mathrm{Al}_{2} \mathrm{O}_{3} / \mathrm{Y}$ TZP composite. Characteristic microstructures were observed by scanning electron microscopy on diamond polished and chemically etched $\left(85 \% \mathrm{H}_{3} \mathrm{PO}_{4}, 7 \mathrm{~min}\right.$ at $\left.200^{\circ} \mathrm{C}\right)$ sample surfaces. The microstructure is very similar for both fabrication techniques, and depends on the zirconia content. Representative scanning electron micrographs of A-5YTZP and A-40YTZP composites are presented in Fig. 1, as a function of Y-TZP reinforcement content. A dense microstructure was observed in all the studied materials, where the alumina matrix (in dark grey) and zirconia particulates (in light grey) were generally well-dispersed. The grain size of $\mathrm{Al}_{2} \mathrm{O}_{3}$ matrix was clearly decreased, as zirconia content increased from 5 to 40 vol. $\%$.
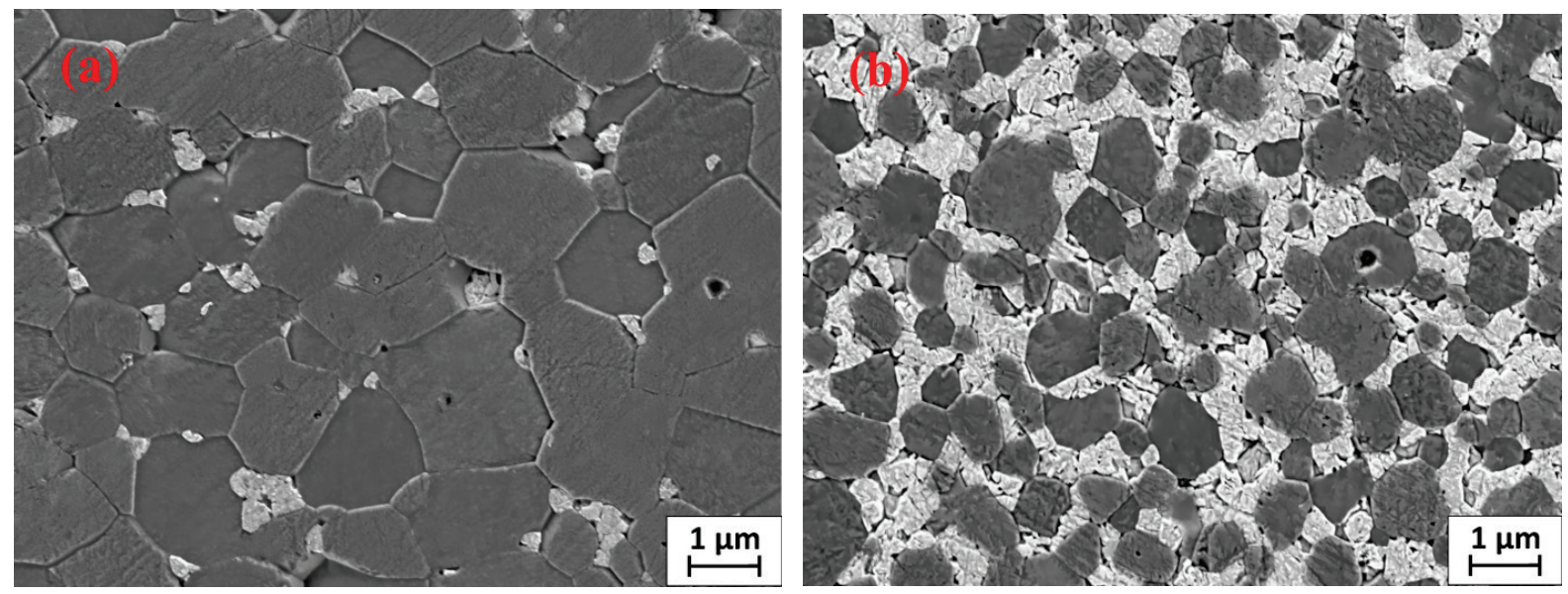

Fig. 1. SEM micrographs of polished and chemically etched surfaces of the studied ceramic composites: (a) A-5YTZP; (b) A-40YTZP. $\mathrm{Al}_{2} \mathrm{O}_{3}$ grains appear with dark grey color and $Y-T Z P$ particulates are in light grey color.

\section{Residual stress measurement}

The time-of-flight neutron diffraction technique ENGIN-X (ISIS, UK) was used for residual strain scanning in each ceramic composite sample (dimensions of $20 \mathrm{~mm} \times 20 \mathrm{~mm} \times 5 \mathrm{~mm}$ ). With two detector banks centered on Bragg angles of $2 \theta_{\mathrm{B}}= \pm 90$ degrees, the ENGIN-X instrument allows simultaneous measurements of strain in two principal stress component directions. In this case, the in-plane direction, parallel to the larger plane of the samples $(20 \mathrm{~mm} \times 20 \mathrm{~mm})$, and the normal direction, perpendicular to it, were chosen. The measurement gauge volume was set to $15 \times 1 \times 1 \mathrm{~mm}^{3}$. Through-thickness strain scanning was carried out along the sample thickness in $0.4 \mathrm{~mm}$ steps. The stress-free reference lattice parameters of $\alpha-\mathrm{Al}_{2} \mathrm{O}_{3}$ and Y-TZP were obtained by measuring both the $\alpha-\mathrm{Al}_{2} \mathrm{O}_{3}$ and $\mathrm{Y}-\mathrm{TZP}$ starting powders.

TOF diffraction data were analyzed by Rietveld refinement of the complete spectrum, using the TOPAS-Academic V5 program [14]. The instrument diffraction profile was modeled by using a convolution of a pseudo-Voigt function with two back-to-back exponentials. Monoclinic zirconia was detected in the Y-TZP powder but not in the composites. Consequently, all the studied A/Y-TZP composites were analyzed by using a two-phase model consisting of the hexagonal $\alpha-\mathrm{Al}_{2} \mathrm{O}_{3}$ phase and tetragonal Y-TZP phase. The space groups and initial atomic structure information used in refinements are taken from [15] [16].

The lattice parameters of each phase were obtained after refinement. The average elastic strain representative of a phase, named mean phase strain, was determined from the change of the average lattice parameters. Mean phase strains for both phases were respectively calculated by averaging the strain over the unit cell, as: 


$$
\bar{\varepsilon}=\left(2 \varepsilon_{a}+\varepsilon_{c}\right) / 3
$$

where $\varepsilon_{a}$ and $\varepsilon_{c}$ are the strains along lattice axis $(a$ and $c)$, calculated as $\varepsilon_{a}=\left(a-a_{0}\right) / a_{0}$, $\varepsilon_{c}=\left(c-c_{0}\right) / c_{0}$, respectively. The lattice parameters $a(a=b)$ and $c$ were obtained from bulk samples, and $a_{0}$ and $c_{0}$ are the stress-free lattice parameters measured from the starting powders.

Taking into account the fabrication process and specimen symmetry, the strains measured in the normal and in-plane directions are considered the principal strains $\varepsilon_{i i}, i=1,2,3$, as $\varepsilon_{11}=\varepsilon_{22}=\varepsilon_{\text {In-plane }}$ and $\varepsilon_{33}=\varepsilon_{\text {Normal }}$. Thus, mean phase stresses for both alumina and zirconia phases were calculated along the in-plane and normal directions using Hooke's law:

$$
\begin{aligned}
& \sigma_{\text {In-plane }}=\frac{E}{1+v} \overline{\mathcal{E}}_{\text {In-plane }}+\frac{E v}{(1+v)(1-2 v)}\left(2 \bar{\varepsilon}_{\text {In-plane }}+\bar{\varepsilon}_{\text {Normal }}\right) \\
& \sigma_{\text {Normal }}=\frac{E}{1+v} \bar{\varepsilon}_{\text {Normal }}+\frac{E v}{(1+v)(1-2 v)}\left(2 \bar{\varepsilon}_{\text {In-plane }}+\bar{\varepsilon}_{\text {Normal }}\right)
\end{aligned}
$$

where $\bar{\varepsilon}$ corresponds to the calculated mean phase strain for both $\mathrm{Al}_{2} \mathrm{O}_{3}$ and Y-TZP phases, given by Eq. 1, and $E$ and $v$ are the bulk elastic constants of $\mathrm{Al}_{2} \mathrm{O}_{3}(E=400 \mathrm{GPa}$ and $v=0.22)$ and Y-TZP $(E=210 \mathrm{GPa}$ and $v=0.31)$ [17].

\section{Results and discussion}

Fig. 2 shows a representative diffraction pattern for a A-40YTZP (tape) composite, including measured (blue line) and calculated profile (red line, overlapping the blue observed profiles). The difference plot between the observed and calculated intensities was shown in grey line below the spectrum. Good fitting was achieved for all reference powders and bulk samples, with the weighted residual error $R_{w p}$ ranging from $4 \%$ to $10 \%$.

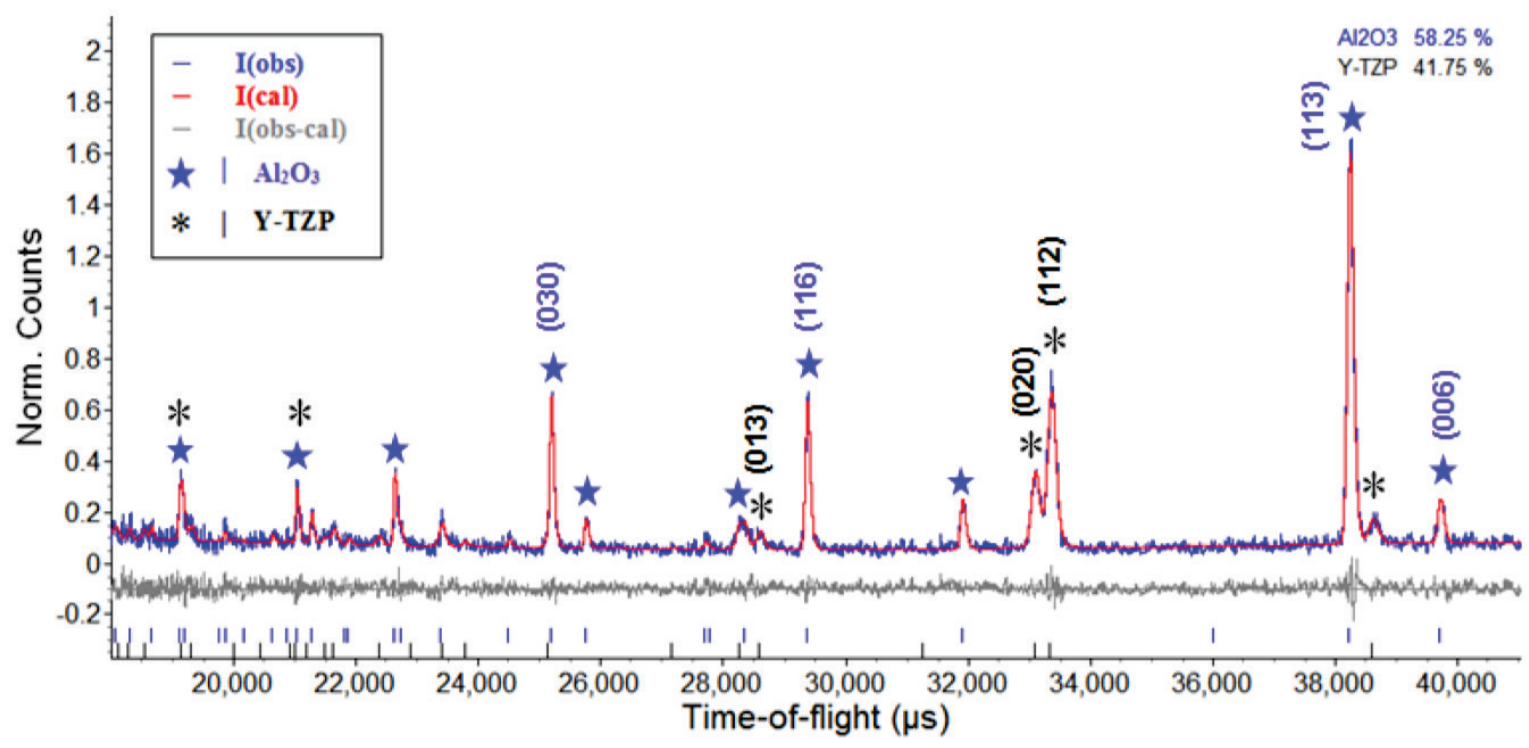

Fig. 2. Representative TOF neutron diffraction pattern analyzed with Rietveld refinement for a A-40YTZP (tape) sample. Individual peaks of $\mathrm{Al}_{2} \mathrm{O}_{3}\left(\star^{*}\right)$ and $\mathrm{Y}-\mathrm{TZP}\left(^{*}\right)$ were identified at the bottom of the profile with blue and black tick marks, respectively. 
Phase composition corresponding to the measured gauge volumes was evaluated by Rietveld refinement, as shown in the upper right of the profile fitting window (Fig. 2). Almost constant Y-TZP contents were recorded at different scanning positions of the same sample, with values very close to the nominal ones.

Through-thickness residual stress profiles of the alumina matrix and the zirconia particulates are shown in Fig. 3 and Fig. 4, for the slip casting and tape casting $\mathrm{Al}_{2} \mathrm{O}_{3} / \mathrm{Y}-\mathrm{TZP}$ samples, respectively. For all the studied $\mathrm{Al}_{2} \mathrm{O}_{3}$ /Y-TZP composites, compressive stresses were found in $\mathrm{Al}_{2} \mathrm{O}_{3}$ matrix and tensile ones were in the Y-TZP particles, This is due to the lower thermal expansion coefficient of $\mathrm{Al}_{2} \mathrm{O}_{3}$ matrix $\left(\alpha_{A, 25-1000^{\circ} \mathrm{C}}=8.6 \times 10^{-6}{ }^{\circ} \mathrm{C}^{-1}\right)$ [18] as compared with Y-TZP particles $\left(\alpha_{Y T Z P, 25-1000^{\circ} \mathrm{C}}=\right.$ $\left.10.8 \times 10^{-6}{ }^{\circ} \mathrm{C}^{-1}\right)$ [19]. Almost flat stress profiles were obtained for both phases in each specimen, which indicates the homogenous distribution of residual stress inside the samples. No obvious orientation effects were discovered, according to the similar stress behaviors in normal and in-plane directions.

In addition, no significant differences can be observed between samples with the same composition made by conventional slip casting (Fig. 3) or by tape casting routes (Fig. 4). This seems to indicate that the low pressure $(18 \mathrm{MPa})$ used for stacking tapes in the novel tape casting green process did not produce additional macro-residual stresses after sintering. Consequently, the microresidual stresses in both phases were mainly induced by thermal and elastic mismatch between phases, during cooling from the sintering temperature to room temperature. Irrespective of the fabrication process (slip casting or tape casting), as Y-TZP content increased from 5 vol. \% to 40 vol. $\%$, tensile stresses in Y-TZP particles decreased from an average value of $730 \pm 50 \mathrm{MPa}$ in A-5YTZP composites to approximately $400 \pm 30 \mathrm{MPa}$ in A-40YTZP composites. On the contrary, the compressive stresses in $\mathrm{Al}_{2} \mathrm{O}_{3}$ matrix were increased (in absolute value) from an average value of $70 \pm 12 \mathrm{MPa}$ in A-5YTZP composites to approximately $-320 \pm 12 \mathrm{MPa}$ in A-40YTZP composites. As the stress profiles are rather flat, the stresses were averaged along the sample thickness, and the reported error is the standard deviation.

The residual stresses were estimated with the modified Eshelby model proposed by Taya et al. [20]. In the model, the isotropic average stress fields in the $\mathrm{Al}_{2} \mathrm{O}_{3}$ matrix and Y-TZP particulate can be theoretically estimated from the volume fraction, elastic modulus, Poisson's ratio and thermal expansion coefficients of the phases. The average residual stresses obtained in both phases are the following:

- A-5YTZP composites: -39 MPa in alumina and $741 \mathrm{MPa}$ in zirconia

- A-40YTZP composites: -326 MPa in alumina and $489 \mathrm{MPa}$ in zirconia

The average residual stresses calculated from the model agree quite reasonably with the ones obtained from the neutron diffraction experiments.

The values of $f_{A} \sigma_{A}+f_{\text {YTZP }} \sigma_{\text {YTZP }}$ were also calculated to check the static equilibrium condition [21], where $f_{A}, f_{\text {YTZP }}$ are the volume fractions of $\mathrm{Al}_{2} \mathrm{O}_{3}$ matrix and Y-TZP in composites; and $\sigma_{A}$, $\sigma_{\text {YTZP }}$ are the measured mean phase stress of $\mathrm{Al}_{2} \mathrm{O}_{3}$ matrix and Y-TZP particulates, respectively. As can be seen in Figs. 3 and 4, those values are close to zero in all cases.

\section{Summary and conclusions}

Through-thickness residual strain scanning was carried out in $\mathrm{Al}_{2} \mathrm{O}_{3} / \mathrm{Y}-\mathrm{TZP}$ ceramic composites with different zirconia content ( 5 and $40 \mathrm{vol} . \%$ ), by means of time-of-flight neutron diffraction. The whole spectra were analyzed with the Rietveld method. The obtained results showed that alumina matrix is under compression and Y-TZP particulates are under tension in the composites, due to thermal expansion mismatch between the matrix and the particles. Almost flat through-thickness mean phase residual stress profiles were obtained in both phases. The novel tape casting process does not produce 
a noticeable change on the residual stress state when compared to the traditional slip casting route. Residual stresses for both phases were mainly dependent on the Y-TZP content in composites.
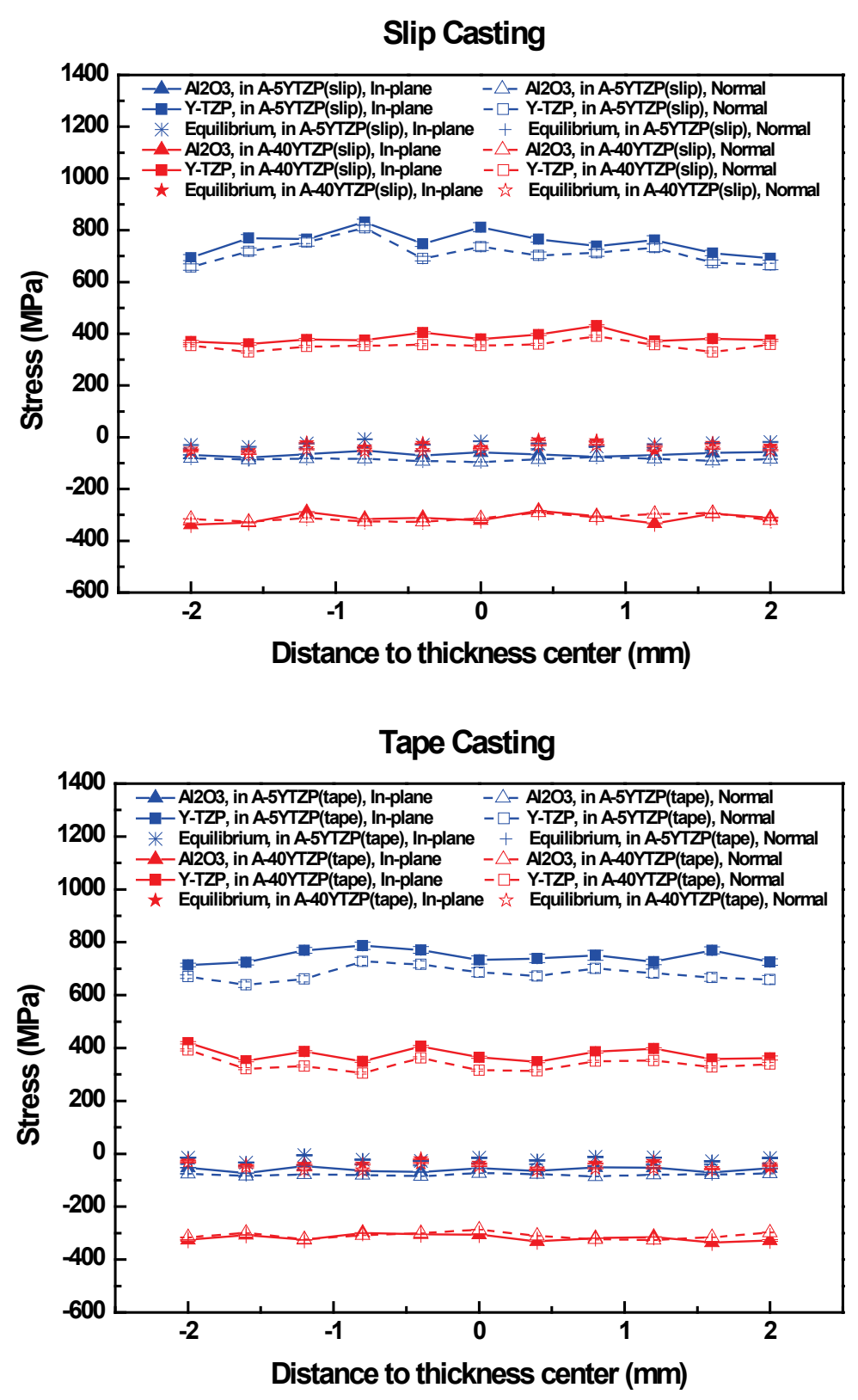

Fig. 3. Mean phase stress profiles for $\mathrm{Al}_{2} \mathrm{O}_{3}(\triangle)$ and $\mathrm{Y}-\mathrm{TZP}(\square)$ phases through the thickness of $A / Y-T Z P$ (slip casting) bulk samples, both in the in-plane (solid line) and normal (dash line) directions. The values of $f_{A} \sigma_{A}+f_{\text {YTZP }} \sigma_{\text {YTZP }}$ were presented without line.
Fig. 4. Mean phase stress profiles for $\mathrm{Al}_{2} \mathrm{O}_{3}(\triangle)$ and $\mathrm{Y}-\mathrm{TZP}$ ( $\square$ ) phases through the thickness of $A / Y-T Z P$ (tape casting) bulk samples, both in the in-plane (solid line) and normal (dash line) directions. The values of $f_{A} \sigma_{A}+f_{\text {YTZP }} \sigma_{\text {YTZP }}$ were presented without line.

\section{Acknowledgements:}

This research has been supported by the Spanish Ministry of Education through grants BIA201126486 and BIA2014-53314-R. EU-NIM3 funding under the program 'Access to ISIS Neutrons' is acknowledged for the measurements at ISIS ENGIN-X. One of the authors (Kunyang Fan) would like to thank China Scholarship Council (CSC) for the grant to do a Ph.D in Spain.

\section{References}

[1] K. Kageyama, Y. Harada, H. Kato, Preparation and mechanical properties of alumina-zirconia composites with agglomerated structures using pre-sintered powder, Mater. Trans., JIM. 44 (2003) 15711576.

[2] F. Gutierrez-Mora, D. Singh, N. Chen, et al., Fracture of composite alumina/yttria-stabilized zirconia joints, J. Eur. Ceram. Soc. 26 (2006) 961-965. http://dx.doi.org/10.1016/j.jeurceramsoc.2004.12.035 
[3] W. Tuan, R. Chen, T. Wang, et al., Mechanical properties of $\mathrm{Al}_{2} \mathrm{O}_{3} / \mathrm{ZrO}_{2}$ composites, J. Eur. Ceram. Soc. 22 (2002) 2827-2833. http://dx.doi.org/10.1016/S0955-2219(02)00043-2

[4] A. Nevarez-Rascon, A. Aguilar-Elguezabal, E. Orrantia, et al., On the wide range of mechanical properties of ZTA and ATZ based dental ceramic composites by varying the $\mathrm{Al}_{2} \mathrm{O}_{3}$ and $\mathrm{ZrO}_{2}$ content, Int. J. Refract. Met. Hard Mater. 27 (2009) 962-970. http://dx.doi.org/10.1016/j.ijrmhm.2009.06.001

[5] K.B. Alexander, P.F. Becher, X.L. Wang, et al., Internal Stresses and the Martensite Start Temperature in Alumina-Zirconia Composites: Effects of Composition and Microstructure, J. Am. Ceram. Soc. 78 (1995) 291-296. http://dx.doi.org/10.1111/j.1151-2916.1995.tb08799.x

[6] C. Baudín, J. Gurauskis, A.J. Sánchez-Herencia, et al., Indentation Damage and Residual Stress Field in Alumina- $\mathrm{Y}_{2} \mathrm{O}_{3}$-Stabilized Zirconia Composites, J. Am. Ceram. Soc. 92 (2009) 152-160. http://dx.doi.org/10.1111/j.1551-2916.2008.02813.x

[7] X.L. Wang, C.R. Hubbard, K.B. Alexander, et al., Neutron Diffraction Measurements of the Residual Stresses in $\mathrm{Al}_{2} \mathrm{O}_{3}-\mathrm{ZrO}_{2}\left(\mathrm{CeO}_{2}\right)$ Ceramic Composites, J. Am. Ceram. Soc. 77 (1994) 1569-1575. http://dx.doi.org/10.1111/j.1151-2916.1994.tb09758.x

[8] T. Adachi, T. Sekino, T. Nakayama, et al., Measurement of microscopic stress distribution of multilayered composite by X-ray stress analysis, Mater. Lett. 57 (2003) 3057-3062. http://dx.doi.org/10.1016/S0167-577X(02)01436-2

[9] G. De Portu, L. Micele, Y. Sekiguchi, et al., Measurement of residual stress distributions in $\mathrm{Al}_{2} \mathrm{O}_{3} / 3 \mathrm{Y}-$ TZP multilayered composites by fluorescence and Raman microprobe piezo-spectroscopy, Acta Mater. 53 (2005) 1511-1520. http://dx.doi.org/10.1016/j.actamat.2004.12.003

[10] J. Ruiz-Hervías, G. Bruno, J. Gurauskis, et al., Neutron diffraction investigation for possible anisotropy within monolithic $\mathrm{Al}_{2} \mathrm{O}_{3} / \mathrm{Y}$-TZP composites fabricated by stacking together cast tapes, Scripta Mater. 54 (2006) 1133-1137. http://dx.doi.org/10.1016/j.scriptamat.2005.11.061

[11] J. Gurauskis, A. Sanchez-Herencia, C. Baudin, Joining green ceramic tapes made from water-based slurries by applying low pressures at ambient temperature, J. Eur. Ceram. Soc. 25 (2005) 3403-3411. http://dx.doi.org/10.1016/j.jeurceramsoc.2004.09.008

[12] J. Gurauskis, A.J. Sánchez-Herencia, C. Baudín, $\mathrm{Al}_{2} \mathrm{O}_{3} / \mathrm{Y}-\mathrm{TZP}$ and Y-TZP materials fabricated by stacking layers obtained by aqueous tape casting, J. Eur. Ceram. Soc. 26 (2006) 1489-1496. http://dx.doi.org/10.1016/j.jeurceramsoc.2005.02.013

[13] A. Tsetsekou, C. Agrafiotis, A. Milias, Optimization of the rheological properties of alumina slurries for ceramic processing applications Part I: Slip-casting, J. Eur. Ceram. Soc. 21 (2001) 363-373. http://dx.doi.org/10.1016/S0955-2219(00)00185-0

[14] A. Coelho, TOPAS-Academic V5, Coelho Software, Brisbane, Australia. http://www.topasacademic.net/ (2012).

[15] J. Lewis, D. Schwarzenbach, H. Flack, Electric field gradients and charge density in corundum, $\alpha-$ $\mathrm{Al}_{2} \mathrm{O}_{3}$, Acta Crystallogr. Sec. A. 38 (1982) 733-739. http://dx.doi.org/10.1107/S0567739482001478

[16] M. Yashima, S. Sasaki, M. Kakihana, et al., Oxygen-induced structural change of the tetragonal phase around the tetragonal-cubic phase boundary in $\mathrm{ZrO}_{2}-\mathrm{YO}_{1.5}$ solid solutions, Acta Crystallogr., Sect. B: Struct. Sci. 50 (1994) 663-672. http://dx.doi.org/10.1107/S0108768194006257

[17] W. Pabst, G. Ticha, E. Gregorova, Effective elastic properties of alumina-zirconia composite ceramics-Part 3. Calculation of elastic moduli of polycrystalline alumina and zirconia from monocrystal data, Ceramics- Silikaty. 48 (2004) 41-48.

[18] T. D, Thermal expansion data. III. Sesquioxides, $\mathrm{M}_{2} \mathrm{O}_{3}$ with the corundum.and the A-, B- and C$\mathrm{M}_{2} \mathrm{O}_{3}$ structures, Br. Ceram. Trans. J. 83 (1984) 92-98.

[19] H. Schubert, Anisotropic Thermal Expansion Coefficients of $\mathrm{Y}_{2} \mathrm{O}_{3}$-Stabilized Tetragonal Zirconia, J. Am. Ceram. Soc. 69 (1986) 270-271. http://dx.doi.org/10.1111/j.1151-2916.1986.tb07424.x

[20] M. Taya, S. Hayashi, A.S. Kobayashi, et al., Toughening of a Particulate-Reinforced Ceramic-Matrix Composite by Thermal Residual Stress, J. Am. Ceram. Soc. 73 (1990) 1382-1391. http://dx.doi.org/10.1111/j.1151-2916.1990.tb05209.x

[21] V. Hauk, Structural and residual stress analysis by nondestructive methods: Evaluation-ApplicationAssessment, Elsevier1997. 